\title{
Desempenho, Parâmetros Plasmáticos e Características de Carcaça de Novilhos Alimentados com Farelo de Girassol e Diferentes Fontes Energéticas, em Confinamento ${ }^{1}$

\author{
Ana Rosália Mendes ${ }^{2}$, Jane Maria Bertocco Ezequiel ${ }^{3}$, Rosemary Laís Galati ${ }^{4}$, José Valmir Feitosa ${ }^{4}$
}

RESUMO - Avaliaram-se consumo, desempenho, parâmetros plasmáticos e características de carcaça de 24 novilhos, 3/4 Simental 1/4 Nelore, com peso médio inicial de $370 \mathrm{~kg}$. As dietas foram compostas por 55\% de silagem de milho e diferentes fontes energéticas: milho (MI) e substituição parcial do milho pela casca de soja (CS) ou pelo farelo de gérmen de milho (FGM), tendo como fonte de proteína o farelo de girassol. O período de avaliação de consumo e ganho de peso foi de 49 dias. Foram realizadas amostragens de sangue para mensuração dos parâmetros plasmáticos: glicose, uréia, proteína total e albumina. As meia-carcaças direitas resfriadas foram utilizadas para medir a área de olho de lombo (AOL), a espessura de gordura (EG) e o comprimento de carcaça. As dietas não influenciaram os parâmetros plasmáticos. A média obtida para uréia plasmática foi elevada $(26,1 \mathrm{mg} / \mathrm{dL})$. As diferentes fontes energéticas não afetaram o ganho de peso e a conversão alimentar, com médias de $1,15 \mathrm{~kg} / \mathrm{dia}$ e $9,17 \mathrm{~kg}$ de MS ingerida $/ \mathrm{kg}$ de ganho. Não houve efeito sobre o rendimento de carcaça $\left(52,8 \%\right.$ peso final e $63,11 \%$ PCV), AOL $\left(63,6 \mathrm{~cm}^{2}\right)$ e EG $(4,7 \mathrm{~mm})$. O grão de milho pode ser substituído parcialmente pela casca de soja e pelo farelo de gérmen de milho, em dietas para novilhos em confinamento, sem afetar o desempenho e as características de carcaça, permitindo que a escolha entre esses ingredientes seja realizada pela análise econômica.

Palavras-chave: área de olho de lombo, casca de soja, espessura de gordura, farelo de gérmen de milho, parâmetros plasmáticos

\section{Performance, Plasma Parameters and Carcass Traits of Steers Fed Diet with Sunflower Meal and Different Energy Sources, in Feedlot}

\begin{abstract}
Performance, plasmatic parameters and carcass traits of 24 3/4 Simmental 1/4 Nellore steers with $370 \mathrm{~kg}$ initial average weight was evaluated. The experimental diets were composed by corn silage (55\%) and concentrate with sunflower meal as protein source and ground corn as energy source (MI). Ground corn was partially substituted by soybean hulls (CS) or by corn meal (FGM). The period of intake and average weight gain evaluation was 49 days. Blood samples were collected to measure plasmatic parameters: glucose, urea, total protein and albumin. Right half frozen carcass was used to measure the loin eye area (LEA), fat thickness (FT) and carcass length. Diets did not influence plasma parameters. The average of plasmatic urea was high $(26 \mathrm{mg} / \mathrm{dL})$, in relation to normal serum pattern. The different energy sources did not affect average weight gain and feed intake:gain ratio, with averages of $1.15 \mathrm{~kg} /$ day and $9.17 \mathrm{~kg}$ DM feed intake/ $\mathrm{kg}$ gain. Diet did not influence dressing percentage ( $52.8 \%$ final weight and $63.1 \%$ of empty body weight), LEA $\left(63.6 \mathrm{~cm}^{2}\right)$ and FT $(4.7 \mathrm{~mm})$. Soybean hulls and corn meal could replace partially ground corn without affecting performance and carcass traits on steers, allowing that the ingredients choice be realized through economic analysis.
\end{abstract}

Key Words: corn germ meal, fat thickness, Longissimus muscle area, plasmatic parameters, soybean hulls

\section{Introdução}

O confinamento é uma das tecnologias usadas para o aumento dos índices de produtividade da pecuária de corte, com reflexos positivos sobre a qualidade das carcaças e a oferta de carne na entressafra (Jorge et al., 1998), e deve-se fazer do confinamento uma atividade lucrativa, pelo qual se tem a maior eficiência do sistema aliada a menor custo (Feijó et al., 1998).
Para a viabilidade e o melhor desempenho na produção de bovinos em confinamento, as dietas devem apresentar elevada concentração de nutrientes e baixo custo. Com o grande crescimento na produção de grãos no Brasil, tornam-se disponíveis subprodutos que não são utilizados para a alimentação humana, mas que possuem qualidade para a introdução na dieta de animais, sendo esses subprodutos geralmente de menor valor comercial.

\footnotetext{
1 Parte integrante da Tese de Doutorado da primeira autora. Projeto financiado pela FAPESP.

2 Médica Veterinária, Doutora em Zootecnia pela FCAV/UNESP, Jaboticabal - SP. E.mail: mendesar@yahoo.com.br

3 Docente do Departamento de Zootecnia da FCAV/UNESP, Via de acesso Prof. Dr. Paulo Donato Castellane, s/n, CEP: 14884-900,

Jaboticabal - SP. E-mail: janembe@fcav.unesp.br

4 Doutores em Zootecnia pela FCAV/UNESP, Jaboticabal - SP.
} 
No ano de 2000/2001, o Brasil produziu cerca de $97.400 \mathrm{t}$ de girassol, sendo grande parte para a produção de óleo vegetal (Agrianual, 2002), disponibilizando o farelo de girassol com casca. Esse farelo apresenta pelo menos $28 \%$ de proteína bruta, sendo uma fonte protéica de baixo custo. Alguns estudos com ruminantes, em fase de crescimento, e com vacas leiteiras indicaram que o valor nutricional do farelo de girassol é equivalente ao farelo de soja e ao farelo de algodão (Richardson, 1981; Vincent et al., 1990). Milton et al. (1997) conduziram um experimento com 384 novilhos com peso médio inicial de $367 \mathrm{~kg}$, no intuito de comparar os farelos de soja e de girassol e suas combinações como fontes protéicas na alimentação de novilhos em fase de terminação sobre o desempenho animal, e observaram que não houve diferença estatística, entre os tratamentos, sobre o consumo de matéria seca, ganho de peso diário e eficiência de ganho. Entretanto, admite-se que a associação do farelo de girassol com diferentes fontes energéticas possa conduzir a melhores ganhos.

O grão de milho é a fonte energética mais utilizada nas dietas de bovinos, mas provoca efeito associativo negativo sobre a digestibilidade da fibra (Hoover, 1986). O uso de fontes energéticas ricas em fibra altamente digestível, como a casca de soja, em dietas mistas de volumosos e concentrados, favorece a digestão da fibra. Animais que receberam dietas contendo casca de soja, em substituição parcial do milho, apresentaram maior digestão da fibra da dieta (Grigsby et al., 1993; Mendes et al., 2005). Essa seria a principal razão pela qual não se observaram diferenças no desempenho de bovinos alimentados com casca de soja em substituição ao milho (Faulkner et al., 1994; Gomes, 1998; Fisher \& Mülhbach, 1999; Thiago et al., 2000).

O farelo de gérmen de milho, produto da extração do óleo do gérmen do milho, é um subproduto produzido em grande escala e com valor nutritivo ainda pouco conhecido, necessitando que estudos sejam realizados com o objetivo de intensificar o seu uso na alimentação animal.

O consumo alimentar é o primeiro passo na formulação de dietas, além de ser a medida com maior associação com a performance animal. Algumas características químicas e/ou físicas do alimento podem afetar positiva ou negativamente a ingestão de matéria seca pelo animal. Segundo Mertens (1993), a densidade energética, quando alta, pode limitar o consumo de matéria seca pelo atendimento do reque- rimento em energia do animal e, quando a densidade for baixa, o consumo será limitado pelo efeito de enchimento do alimento. Bernard \& McNeill (1991), utilizando dietas com milho, glúten de milho, farelo de trigo e casca de soja para vacas leiteiras, observaram maior ingestão de FDN e FDA quando utilizaram a casca de soja, porém, a ingestão de matéria seca foi semelhante às dietas com milho e glúten de milho.

O monitoramento de alguns parâmetros sanguíneos favorece a investigação de ingredientes ainda pouco conhecidos. No ruminante, o amido que não sofre fermentação ruminal, posteriormente, é digerido no intestino delgado liberando glicose (Waldo, 1973). A importância do metabolismo da glicose para ruminantes é reconhecida há alguns anos e, mais recentemente, alguns trabalhos têm enfocado uma descrição quantitativa do metabolismo da glicose em ruminantes e o controle do metabolismo por meio das condições hormonais (Weeks, 1991). No tocante às proteínas, Payne \& Payne (1987) citaram uréia e albumina como os principais indicadores do estado protéico animal, sendo a dieta responsável pelo nível sérico.

A avaliação de carcaças de bovinos é importante por indicar características de qualidade e de rendimento de carne. Portanto as carcaças devem ser avaliadas com base no peso, acabamento, comprimento, espessura da gordura, área de olho de lombo (AOL), entre outras. O peso de abate, o sexo, a nutrição e a raça afetam a composição da carcaça e são os principais fatores sobre os quais técnicos podem intervir, visando à alteração dessa composição (Luchiari Filho, 2000).

Objetivou-se avaliar o efeito da substituição parcial do milho pela casca do grão de soja ou pelo farelo de gérmen de milho, associado ao farelo de girassol como fonte protéica, sobre o consumo de nutrientes, digestibilidade da matéria seca, desempenho, parâmetros plasmáticos e características de carcaça de novilhos de corte confinados.

\section{Material e métodos}

O experimento foi realizado na Fazenda Santa Luzia, município de Apucarana-PR, no período de junho a agosto de 2001. Foram utilizados 24 novilhos, 3/4 Simental 1/4 Nelore, com idade inicial de aproximadamente 24 meses e peso médio inicial de $370 \mathrm{~kg}$. Os animais foram divididos em 12 baias de 15

R. Bras. Zootec., v.34, n.2, p.692-702, 2005 
$\mathrm{m}^{2}$, pavimentadas, parcialmente cobertas. O período de confinamento foi de 73 dias, sendo os primeiros 24 dias utilizados para a adaptação à dieta e uniformização do consumo, não sendo considerados para as avaliações de consumo e ganho de peso.

As composições químicas dos ingredientes utilizados na formulação das dietas encontram-se na Tabela 1. As dietas foram fornecidas para que houvesse sobras de 5 a $10 \%$, duas vezes ao dia, pela manhã e ao final da tarde, sendo as sobras de alimentos retiradas e pesadas diariamente e amostradas três vezes por semana, para avaliação do consumo por baia. As amostras de silagem de milho e de sobras diárias foram pré-secas a $55^{\circ} \mathrm{C}$, por 72 horas.

Todas as amostras foram compostas por baia e por semana. Os ingredientes e as sobras foram moídos, em peneira de 16 mesh $(1 \mathrm{~mm})$, para determinação dos teores de matéria seca (MS), matéria orgânica (MO), proteína bruta pelo método Kjeldahl (PB) e extrato etéreo (EE), segundo o AOAC (1995). Fibra em detergente neutro (FDN) e fibra em detergente ácido (FDA) foram analisadas utilizando-se as soluções citadas por Silva (1990), e a digestão submetida a controle de temperatura e pressão em autoclave por 40 minutos a $0,5 \mathrm{~atm}$ e $111^{\circ} \mathrm{C}$, pelo método sequencial. A lignina foi determinada pelo método do ácido sulfúrico $72 \%$, descrito no AOAC (1995).
As dietas foram compostas com 55\% de volumoso, silagem de milho e $45 \%$ de concentrado. Foram estudadas três dietas experimentais com diferentes fontes energéticas: milho (MI), milho substituído parcialmente pela casca de soja (CS) ou pelo farelo de gérmen de milho (FGM), tendo como fonte de proteína o farelo de girassol, sendo calculadas de acordo com as exigências do NRC (1996) para ganho de $1,2 \mathrm{~kg}$ e de forma a serem isoprotéicas (Tabela 2).

Os animais foram pesados no início do período de adaptação, no início do período de avaliação do consumo e ganho de peso e no final do experimento, com jejum alimentar e hídrico de 14 horas. O período de avaliação do consumo e do ganho de peso foi de 49 dias.

Foram realizadas amostragens de sangue da veia jugular para mensuração dos parâmetros plasmáticos: glicose, uréia, proteína total e albumina, nos dias 0, 21, 35 e 49 após a adaptação, no período da manhã, antes da alimentação, e calculadas as médias por animal. Nas amostras destinadas à determinação da glicose, houve adição de uma gota de fluoreto/mL de sangue. Todas as amostras foram centrifugadas, imediatamente após a colheita, a $3.000 \mathrm{rpm}$ por 15 minutos, e os sobrenadantes foram congelados e encaminhados ao Laboratório de Análises Clínicas do Hospital Veterinário da FCAV/ UNESP, Campus de Jaboticabal.

Tabela 1- Composição química dos ingredientes utilizados nas dietas

Table 1 - Chemical composition of ingredients used in the diets

\begin{tabular}{|c|c|c|c|c|c|}
\hline & \multicolumn{4}{|c|}{$\begin{array}{l}\text { Ingrediente } \\
\text { Ingredient }\end{array}$} & \multirow[b]{2}{*}{$\begin{array}{c}\text { Farelo de girassol } \\
\text { Sunflowermeal }\end{array}$} \\
\hline & $\begin{array}{l}\text { Silagem de milho } \\
\text { Corn silage }\end{array}$ & $\begin{array}{l}\text { Milho grão } \\
\text { Corn grain }\end{array}$ & $\begin{array}{l}\text { Casca de soja } \\
\text { Soybean hulls }\end{array}$ & $\begin{array}{l}\text { Farelo de gérmen de milho } \\
\text { Corn germ meal }\end{array}$ & \\
\hline $\begin{array}{l}\text { Matéria seca }(\%) \\
\text { Dry matter }(\%)\end{array}$ & 39,0 & 86,9 & 88,9 & 88,0 & 89,0 \\
\hline $\begin{array}{l}\text { Matéria orgânica } \\
\text { Organic matter }\end{array}$ & 94,6 & 98,7 & $\begin{array}{c}\% \mathrm{MS}(\% \mathrm{DM}) \\
95,7\end{array}$ & 95,2 & 95,2 \\
\hline $\begin{array}{l}\text { Proteína bruta } \\
\text { Crude protein }\end{array}$ & 5,6 & 9,2 & 11,1 & 12,8 & 33,1 \\
\hline $\begin{array}{l}\text { FDN } \\
N D F\end{array}$ & 60,2 & 14,5 & 69,7 & 32,5 & 46,0 \\
\hline $\begin{array}{l}\text { FDA } \\
A D F\end{array}$ & 27,4 & 3,6 & 48,8 & 5,7 & 29,8 \\
\hline $\begin{array}{l}\text { Celulose } \\
\text { Cellulose }\end{array}$ & 24,7 & 2,8 & 47,7 & 4,9 & 22,3 \\
\hline $\begin{array}{l}\text { Lignina } \\
\text { Lignin }\end{array}$ & 2,7 & 0,8 & 1,1 & 0,8 & 7,5 \\
\hline $\begin{array}{l}\text { Extrato etéreo } \\
\text { Ether extract }\end{array}$ & 0,6 & 5,1 & 2,3 & 2,3 & 1,9 \\
\hline
\end{tabular}

\section{R. Bras. Zootec., v.34, n.2, p.692-702, 2005}


Tabela 2 - Composição percentual e química das dietas experimentais

Table 2 - Percentual and chemical composition of the experimental diets

\begin{tabular}{|c|c|c|c|}
\hline \multirow[t]{2}{*}{$\begin{array}{l}\text { Ingrediente (\%) } \\
\text { Ingredient }(\%)\end{array}$} & \multicolumn{3}{|c|}{$\begin{array}{c}\text { Dieta } \\
\text { Diet }\end{array}$} \\
\hline & MI & $\mathrm{CS}$ & FGM \\
\hline Silagem de milho & 55,0 & 55,0 & 55,0 \\
\hline $\begin{array}{l}\text { Corn silage } \\
\text { Milho grão }\end{array}$ & 19,2 & 10,2 & 10,5 \\
\hline Corn grain & & & \\
\hline $\begin{array}{l}\text { Casca de soja } \\
\text { Soybean hulls }\end{array}$ & - & 9,9 & - \\
\hline $\begin{array}{l}\text { Farelo de gérmen de milho } \\
\text { Corn germ meal }\end{array}$ & - & - & 9,8 \\
\hline $\begin{array}{l}\text { Farelo de girassol } \\
\text { Sunflower meal }\end{array}$ & 25,1 & 24,2 & 24,0 \\
\hline $\begin{array}{l}\text { Suplemento mineral } \\
\text { Mineral supplement }\end{array}$ & 0,7 & 0,7 & 0,7 \\
\hline $\begin{array}{l}\text { Composição química (\% M } \\
\text { Chemical composition }(\% D M)\end{array}$ & & & \\
\hline $\begin{array}{l}\text { Matéria orgânica } \\
\text { Organic matter }\end{array}$ & 95,6 & 95,3 & 95,3 \\
\hline $\begin{array}{l}\text { Proteína bruta } \\
\text { Crude protein }\end{array}$ & 13,1 & 13,1 & 13,2 \\
\hline $\begin{array}{l}\text { FDN } \\
N D F\end{array}$ & 47,4 & 52,6 & 48,8 \\
\hline $\begin{array}{l}\text { FDA } \\
A D F\end{array}$ & 23,2 & 27,5 & 23,1 \\
\hline $\begin{array}{l}\text { Celulose } \\
\text { Cellulose }\end{array}$ & 19,8 & 24,1 & 19,8 \\
\hline $\begin{array}{l}\text { Lignina } \\
\text { Lignin }\end{array}$ & 3,4 & 3,4 & 3,3 \\
\hline $\begin{array}{l}\text { Extrato etéreo } \\
\text { Ether extract }\end{array}$ & 1,8 & 1,5 & 1,5 \\
\hline
\end{tabular}

$\mathrm{MI}=$ dieta formulada com milho; $\mathrm{CS}=$ substituição parcial do milho pela casca de soja; FGM = substituição parcial do milho pelo farelo de gérmen de milho.

$M I=$ diet formulated with corn; $C S$ = corn partial substitution for soybean hulls; FGM = corn partial substitution for corn germ meal.

A concentração plasmática de glicose foi determinada pelo método enzimático-colorimétrico da glicose-oxidase, com a utilização de kit comercial (Sigma C.C.). A uréia plasmática, a albumina e a proteína total foram dosificadas utilizando-se kits comerciais (Doles, Sigma C.C. e Sigma C. C., respectivamente) pelo método químico colorimétrico.

Durante quatro dias consecutivos, na última semana experimental, foram coletadas amostras de fezes dos 24 animais para se estimar a digestibilidade da dieta através do FDA indigestível. As amostras de fezes, assim como as de alimento e de sobras foram pré-secas a $55^{\circ} \mathrm{C}$ por 72 horas e compostas por animal.

A porcentagem de FDAi foi quantificada após 144 horas de incubação in vitro de $0,5 \mathrm{~g}$ de amostra. Utilizou-se saliva artificial e líquido ruminal na pro- porção de 4:1, em um único estádio de digestão, segundo o método de Tilley \& Terry, citados por Silva (1990). Após a incubação, os tubos foram colocados a $5^{\circ} \mathrm{C}$ para interromper parcialmente a digestão, e os conteúdos quantitativamente transferidos para os copos de Berzelius (600 mL). Adicionaram-se $50 \mathrm{~mL}$ de solução detergente ácida, e procedeu-se à determinação da FDA, conforme o método descrito por Silva (1990).

Após os 49 dias de período experimental, 21 animais foram abatidos na Indústria e Comércio de Carnes Minerva, Barretos - SP, sendo avaliados o peso da carcaça quente (PCQ), peso da carcaça fria (PCF) e o rendimento de carcaça. O peso corporal vazio (PCV) foi calculado, somando-se o PCQ e os pesos de todos os órgãos, cabeça, patas, couro, sangue, cauda e trato digestório vazio de cada animal. Três animais não foram abatidos pela indisponibilidade de transporte.

As carcaças foram levadas à câmara de resfriamento onde permaneceram durante 24 horas à temperatura de $1^{\circ} \mathrm{C}$ a $2^{\circ} \mathrm{C}$. As meia-carcaças direitas resfriadas foram utilizadas para medir a área de olho de lombo (AOL), a espessura de gordura (EG) e o comprimento de carcaça. Para avaliação da AOL, o músculo Longissimus dorsi foi seccionado transversalmente entre a $12^{\underline{a}}$ e $13^{\mathrm{a}}$ costela, traçando o seu contorno em papel vegetal. A área foi determinada utilizando-se o aparelho Digital Image Analysis System, Version 1.12 (C) 1993, Delta T Devices, Ltda. AEG foi medida em mm, na altura da $12{ }^{2}$ costela, sobre a secção do músculo Longissimus dorsi, em três pontos, considerando-se a média. O comprimento de carcaça foi obtido medindo-se do bordo anterior medial da $1^{\mathrm{a}}$ costela ao bordo anterior do púbis.

$\mathrm{O}$ delineamento experimental utilizado foi o inteiramente casualizado, e os resultados obtidos foram submetidos à análise de variância pelo procedimento GLM do SAS ® (1995), e as diferenças entre médias comparadas pelo teste Tukey (5 e 1\%).

\section{Resultados e Discussão}

As médias de ingestão de matéria seca e dos nutrientes avaliados nas dietas, os coeficientes de digestibilidade da matéria seca e os coeficientes de variação encontram-se na Tabela 3.

As diferentes fontes energéticas não influenciaram $(\mathrm{P}>0,05)$ o consumo de matéria seca, expresso por $\%$ do peso médio durante o período de

R. Bras. Zootec., v.34, n.2, p.692-702, 2005 
Tabela 3 - Consumo diário de matéria seca (IMS), matéria orgânica $(\mathrm{MO})$, proteína bruta $(\mathrm{PB})$, extrato etéreo (EE), fibra em detergente neutro (FDN), fibra em detergente ácido (FDA), lignina e coeficiente de digestibilidade aparente da matéria seca (CDMS)

Table 3 - Daily intake of dry matter (DMI), organic matter $(O M)$, crude protein $(C P)$, ether extract $(E E)$, neutral detergent fiber (NDF), acid detergent fiber (ADF), cellulose (Cel), lignin and coefficient of apparent digestibility (CAD)

\begin{tabular}{|c|c|c|c|c|}
\hline & \multicolumn{3}{|c|}{$\begin{array}{c}\text { Dieta } \\
\text { Diet }\end{array}$} & \multirow[b]{2}{*}{$\mathrm{CV}(\%)$} \\
\hline & MI & $\mathrm{CS}$ & FGM & \\
\hline IMS (kg/animal/dia) & 10,75 & 10,55 & 10,39 & 3,26 \\
\hline DMI (kg/animal/day) & & & & \\
\hline $\begin{array}{l}\text { IMS, } \% \text { peso médio } \\
\text { DMI (\% average weight) }\end{array}$ & 2,50 & 2,57 & 2,52 & 5,29 \\
\hline $\begin{array}{l}\text { IMS }(\mathrm{g} / \mathrm{kg} \text { peso } \\
\text { DMI }(\text { g/body weight }\end{array}$ & 98,98 & 109,35 & 100,43 & 22,23 \\
\hline $\begin{array}{l}\mathrm{MO} \text { (kg/animal/dia) } \\
\text { OM (kg/animal/day) }\end{array}$ & 10,19 & 9,98 & 9,85 & 3,49 \\
\hline $\begin{array}{l}\mathrm{PB} \text { (kg/animal/dia) } \\
C P \text { (kg/animal/day) }\end{array}$ & $1,46 \mathrm{a}$ & $1,42 \mathrm{a}$ & $1,35 b$ & 3,78 \\
\hline $\begin{array}{l}\mathrm{EE}(\mathrm{kg} / \mathrm{animal} / \mathrm{dia}) \\
\text { EE }(\mathrm{kg} / \text { animal/day })\end{array}$ & 0,11 & 0,10 & 0,10 & 5,57 \\
\hline $\begin{array}{l}\text { FDN (kg/animal/dia) } \\
N D F(\mathrm{~kg} / \text { animal/day })\end{array}$ & 5,43 & 5,60 & 5,28 & 5,31 \\
\hline $\begin{array}{l}\text { FDA (kg/animal/dia) } \\
A D F \text { (kg/animal/day) }\end{array}$ & $2,59 b$ & $2,95 \mathrm{a}$ & $2,66 a b$ & 9,15 \\
\hline $\begin{array}{l}\text { Lignina (kg/animal/dia) } \\
\text { Lignin (kg/animal/day) }\end{array}$ & 0,36 & 0,34 & 0,34 & 6,89 \\
\hline $\begin{array}{l}\text { CDMS }(\%) \\
C A D(\%)\end{array}$ & 53,91 & 52,39 & 51,95 & 7,71 \\
\hline
\end{tabular}

Médias seguidas de letras diferentes na mesma coluna, diferem $(\mathrm{P}<0,01)$ pelo teste de Tukey. $\mathrm{MI}=$ dieta formulada com milho; $\mathrm{CS}$ = substituição parcial do milho pela casca de soja; FGM = substituição parcial do milho pelo farelo de gérmen de milho. CV = coeficiente de variação.

Means followed by different letters in the column are different by Tukey test $(P<.01) . M I=$ diet formulated with corn; $C S=$ corn partial substitution for soybean hulls; $F G M=$ corn partial substitution for corn germ meal. $C V=$ coefficient of variation.

confinamento ou por peso metabólico. Estes resultados são compatíveis aos relatados por Thiago et al. (2000), que avaliaram quatro níveis de substituição do milho pela casca de soja, e não encontraram efeito sobre o consumo de MS, com média de $2,4 \%$ do peso vivo, em novilhos Nelore.

No entanto Fischer \& Mühlbach (1999), avaliando a substituição do milho pela casca de soja em dietas com aproximadamente $56 \%$ de silagem de milho fornecidas para novilhas sem raça definida, encontraram efeito linear crescente da substituição do milho pela casca de soja sobre o consumo de MS. Estes autores sugeriram que a menor ocorrência de efeitos negativos sobre a digestão da fibra pode ter favorecido o maior consumo, ou a menor densidade energética da casca de soja, possivelmente, possa ter levado os animais a incrementar o consumo para compensar o menor nível de ingestão de energia.

A ingestão de proteína bruta foi maior $(\mathrm{P}<0,05)$ para a dieta MI em relação à FGM. Levando-se em consideração o teor de proteína bruta das dietas $(13,15 \%)$ e, de acordo com a ingestão de matéria seca, a dieta MI proporcionaria a ingestão de 47,3 g a mais de proteína bruta do que a dieta FGM. No entanto a ingestão de proteína bruta da dieta MI foi de $110 \mathrm{~g}$ a mais do que da dieta FGM, indicando menor ingestão de concentrado pelos animais alimentados com a dieta com farelo de gérmen de milho (FGM). $\mathrm{O}$ que também pode ser justificado pelo valor numericamente mais elevado de ingestão de FDA da dieta FGM, quando comparada à MI, sendo que as duas apresentam teor praticamente semelhante deste nutriente. Isso pode ser explicado pela granulometria do farelo de gérmen de milho que, apesar de ser comercializado peletizado, possui partículas muito pequenas que se aderem à fibra da silagem, aumentando a porcentagem de proteína bruta das sobras. O pequeno tamanho de partícula do farelo de gérmen de milho também foi indicado por Galati et al. (2002a). Estes autores, em experimento de degradabilidade, observaram elevado valor da fração solúvele associaram à possível passagem de pequenas partículas pelos poros dos sacos de náilon, oriundas do farelo.

A ingestão de FDN não foi influenciada pelas diferentes fontes energéticas e apresentou valor médio de $5,44 \mathrm{~kg} / \mathrm{animal} / \mathrm{dia}$. Os valores de ingestão de FDN, expressos em porcentagem do peso médio, foram de 1,26; 1,36 e 1,28\%, valores próximos ao máximo relatado por Ferreira et al. (1999), que avaliaram diferentes níveis de concentrado em dietas para novilhos Simental x Nelore e observaram valor de $1,35 \%$ do peso vivo em dietas com $25 \%$ de concentrado e de $0,96 \%$, em dietas com $50 \%$ de concentrado. Esses valores mais altos de ingestão de fibra nas dietas desse experimento são causados pela maior porcentagem de fibra do farelo de girassol (46,0\% de FDN), quando comparado ao farelo de soja, fonte protéica usualmente utilizada nos concentrados.

Houve efeito significativo $(\mathrm{P}<0,05)$ na ingestão de FDA, com maiores valores para a dieta CS, quando comparada à MI. No entanto essa maior ingestão de FDA não foi suficiente para influenciar o consumo de matéria seca dos animais, possivelmente 
pelas características da fibra da casca de soja, que possui alta digestão ruminal, ou pela maior taxa de passagem desse ingrediente. Mendes et al. (2005), estudando dietas semelhantes às pesquisadas neste experimento, encontraram valores de digestibilidade da FDA maiores para a dieta com casca de soja e não observaram efeito da maior ingestão de FDA sobre o consumo de matéria seca. Esses resultados corroboram os relatados por Bernard \& McNeil (1991) e Mansfield \& Stern (1994), que avaliaram a substituição do milho pela casca de soja e encontraram maiores valores de ingestão de fibra nas dietas com casca de soja, não afetando, porém, o consumo de matéria seca.

As médias dos coeficientes de digestibilidade da matéria seca, obtidas neste experimento, não apresentaram diferença significativa entre as diferentes dietas. Resultados semelhantes foram encontrados por Mendes et al. (2005), que não verificaram diferença significativa para a digestibilidade total da matéria seca, com médias de 60,4; 59,0 e $59,2 \%$ para dietas com milho, casca de soja e farelo de gérmen de milho, respectivamente. No entanto essas médias são superiores às encontradas neste experimento. Possivelmente, a maior granulometria do concentrado possa ter influenciado os menores valores de digestibilidade encontrados neste experimento, já que os ingredientes foram moídos em peneira de $5 \mathrm{~mm}$, enquanto no experimento de Mendes et al. (2005), o concentrado foi moído em peneira de $3 \mathrm{~mm}$. Outros fatores que também possam ter afetado os valores de digestibilidade são a metodologia, o indicador utilizado, e as características digestivas individuais dos animais deste experimento. Onível de consumo, por sua vez, é um fator que também pode influenciar a digestibilidade da dieta. Neste experimento, o consumo de matéria seca foi $13,4 \%$ superior (10,56 vs $9,14 \mathrm{~kg} / \mathrm{dia})$ ao relatado por Mendes et al. (2005).

$\mathrm{Na}$ Tabela 4, encontram-se as médias das concentrações plasmáticas de glicose, uréia, proteína total e albumina. A quantidade de carboidratos nãoestruturais da dieta pode afetar a concentração sérica de glicose (López \& Stumpf Jr., 2000). Nesta pesquisa, a relação volumoso:concentrado foi constante (55:45). No entanto as diferentes fontes energéticas poderiam disponibilizar ao animal quantidades distintas de glicose, de acordo com a produção de ácido propiônico durante a fermentação ruminal e subseqüente produção de glicose; ou com a quantidade de amido
Tabela 4 - Médias dos parâmetros plasmáticos de acordo com as dietas experimentais

Table 4 - Plasma parameters averages of each experimental diet

\begin{tabular}{|c|c|c|c|c|}
\hline & \multicolumn{3}{|c|}{$\begin{array}{l}\text { Dieta } \\
\text { Diet }\end{array}$} & \multirow[b]{2}{*}{$\mathrm{CV}(\%)$} \\
\hline & MI & $\mathrm{CS}$ & FGM & \\
\hline Glicose (mg/dL) & 80,29 & 80,04 & 71,75 & 12,28 \\
\hline Glucose (mg/dL) & & & & \\
\hline $\begin{array}{l}\operatorname{Uréia}(\mathrm{mg} / \mathrm{dL}) \\
\operatorname{Urea}(m g / d L)\end{array}$ & 26,58 & 25,85 & 25,74 & 10,93 \\
\hline $\begin{array}{l}\text { Proteína total }(\mathrm{g} / \mathrm{dL}) \\
\text { Total protein }(\mathrm{g} / \mathrm{dL})\end{array}$ & 7,88 & 8,09 & 7,80 & 4,15 \\
\hline $\begin{array}{l}\text { Albumina }(\mathrm{g} / \mathrm{dL}) \\
\operatorname{Albumin}(\mathrm{g} / \mathrm{dL})\end{array}$ & 3,53 & 3,61 & 3,61 & 6,59 \\
\hline
\end{tabular}

Médias em linhas não diferem entre si pelo teste de Tukey $(P>0,01) . M I=$ dieta formulada com milho; $C S=$ substituição parcial do milho pela casca de soja; FGM = substituição parcial do milho pelo farelo de gérmen de milho. $\mathrm{CV}=$ coeficiente de variação.

Means within a row do not differ by Tukey test $(P>$.01). $M I=$ diet formulated with corn; $C S=$ corn partial substitution for soybean hulls; $F G M=$ corn partial substitution for corn germ meal. CV = coefficient of variation.

sobrepassante, sendo digerido e aproveitado como fonte direta de glicose. Porém as substituições parciais do milho pelo farelo de gérmen de milho e pela casca de soja não influenciaram $(\mathrm{P}>0,05)$ as concentrações plasmáticas de glicose. Resultados similares aos relatados por Simas et al. (2000), que avaliando diferentes fontes de amido em dietas para vacas, não encontraram diferença significativa entre as fontes, com média de 56,6 mg/dL. Lycos et al. (1997), estudando dietas com diferentes proporções de carboidratos não-estruturais degradados no rúmen, também não observaram diferença entre as médias $(69,5 \mathrm{mg} / \mathrm{dL})$. A grande amplitude de variação dos valores observados para a concentração sérica de glicose pode decorrer do exercício físico ou estresse a que os animais são submetidos no momento da colheita de sangue (Svendsen, 1976).

Segundo Broderick \& Clayton (1997), a concentração de $\mathrm{N}$-uréia sanguínea tem sido utilizada para monitorar o consumo de proteína dietética, cujo excesso pode afetar o desempenho reprodutivo, aumentar a exigência em energia e encarecer as dietas, já que as fontes protéicas são os ingredientes mais caros. As médias das concentrações plásmáticas de uréia não diferiram entre as diferentes dietas, provavelmente pelo fato de possuírem a mesma porcentagem de proteína bruta (13\% de PB/MS), fornecida notadamente pela mesma fonte protéica, o farelo de girassol. 
Butler et al., citados por Miranda et al. (1998), relataram que a quantidade de amônia produzida no rúmen, que é absorvida e convertida em uréia no fígado, reflete os níveis de consumo de proteína degradável dietética e a viabilidade de carboidratos fermentáveis para suportar crescimento microbiano e síntese de proteína. Simas et al. (2000), avaliando diferentes fontes de amido, e de acordo com os níveis de amônia ruminal e uréia plasmática, sugeriram metabolismo protéico mais eficiente em dietas com milho floculado, quando comparado ao moído.

Os valores de uréia plasmática encontrados neste trabalho são mais elevados que os relatados por Miranda et al. (1998), que utilizaram dietas com 50\% da proteína da dieta $(13 \% \mathrm{~PB} / \mathrm{MS})$ fornecida como nitrogênio não-protéico, encontraram em média 15,4 mg de N-uréia/dL, em novilhas. A média dos valores encontrados para as concentrações de uréia plasmática neste estudo $(26,1 \mathrm{mg} / \mathrm{dL})$ encontra-se próxima ao limite máximo dentro da faixa de normalidade $(6,0$ - 27,0 mg/dL), de acordo com Guia (2000). Isso pode indicar falta de sincronização na degradação do nitrogênio e carboidratos no rúmen. De acordo com Galati et al. (2002b), o farelo de girassol apresenta elevado valor de solubilidade e é extensivamente degradado no rúmen, com taxa de degradação da proteína bruta de 9,9\%/h. Essa degradação rápida da principal fonte protéica da dieta no rúmen pode não ter permitido a otimização da fermentação ruminal, o que estimularia a maior produção de proteína microbiana e diminuição do nível de uréia plasmática.

Existe alta correlação entre nível de uréia plasmática e $\mathrm{N}-\mathrm{NH}_{3}$ ruminal (Kennedy \& Milligan, 1980). Galati et al. (2002c) avaliando a concentração de $\mathrm{N}-\mathrm{NH}_{3}$ ruminal em dietas com milho, casca de soja ou farelo de gérmen de milho associados ao farelo de girassol, não encontraram diferença entre as dietas, com média de $26,1 \mathrm{mg}$ de $\mathrm{N}-\mathrm{NH}_{3} / 100 \mathrm{~mL}$ de líquido ruminal.

Os valores das concentrações de albumina e proteína total sérica não foram influenciados pelas fontes energéticas, apresentando valores médios de 7,92 e $3,58 \mathrm{~g} / \mathrm{dL}$, respectivamente. Esses valores encontram-se dentro da amplitude normal de variação, 6,7 a 7,5 mg/dL, e 3,0 a 3,6 mg/dL para proteína e albumina sérica, respectivamente (Smith, 1993), indicando que os animais estavam ingerindo quantidade adequada de proteína metabolizável para a manutenção dos níveis séricos. A média observada para albumina está próxima ao valor relatado por Steen (1989) em dietas com cevada e farelo de girassol, em novilhos, com média de 3,6 mg/dL.

As médias de peso inicial, peso final, ganho de peso diário (GPD), ingestão de matéria seca, conversão alimentar (CA) e eficiência alimentar de proteína bruta (EAPB) para as dietas MI, CS e FGM encontram-se na Tabela 5.

Não houve diferenças significativas para peso inicial e peso final. As variações encontradas para peso inicial foram decorrentes da diferença na resposta animal durante o período de adaptação, não possibilitando valores médios mais próximos.

A substituição parcial do milho pela casca de soja ou pelo farelo de gérmen de milho não influenciou ( $\mathrm{P}>0,05)$ o ganho de peso, no entanto o valor médio observado para CS foi $5,13 \%$ inferior aos ganhos diários com as demais dietas. Esses resultados são distintos dos observados por Thiago et al. (2000), que encontraram valores de ganho de peso inferiores para animais da raça Nelore, alimentados com silagem

Tabela 5 - Médias de peso inicial, peso final, ganho de peso diário (GPD), ingestão de matéria seca, conversão alimentar (CA) e eficiência alimentar de PB (EAPB), de acordo com as dietas experimentais

Table 5 - Averages of initial body weight, final body weight, weight daily gain (WDG), dry matter intake, intake/ gain ratio and gain/crude protein intake ratio, of each experimental diet

\begin{tabular}{lcccc}
\hline & \multicolumn{3}{c}{$\begin{array}{c}\text { Dieta } \\
\text { Diet }\end{array}$} & \\
\cline { 2 - 4 } & MI & CS & FGM & CV $(\%)$ \\
\hline $\begin{array}{l}\text { Peso inicial (kg) } \\
\text { Initial body weight }(\mathrm{kg})\end{array}$ & 402,86 & 382,86 & 388,28 & 4,6 \\
$\begin{array}{l}\text { Peso final (kg) } \\
\text { Final body weight }(\mathrm{kg})\end{array}$ & 460,43 & 437,14 & 445,71 & 4,7 \\
$\begin{array}{l}\text { GPD (kg/dia) } \\
\text { WDG (kg) }\end{array}$ & 1,17 & 1,11 & 1,17 & 20,6 \\
$\begin{array}{l}\text { Ingestão de MS (kg) } \\
\text { Dry matter intake (kg) }\end{array}$ & 10,72 & 10,48 & 10,43 & 3,2 \\
$\begin{array}{l}\text { CA (MS ingerida/ganho) } \\
\text { F/G (DM intake/gain ratio) }\end{array}$ & 9,11 & 9,51 & 8,89 & 15,6 \\
$\begin{array}{l}\text { EAPB (kg ganho/ } \\
\text { kg PB ingerida) }\end{array}$ & 0,81 & 0,77 & 0,87 & 19,1 \\
\begin{tabular}{l} 
Gain/CP intake ratio \\
\hline
\end{tabular} & & & & \\
\hline
\end{tabular}

Médias em linhas não diferem entre si pelo teste de Tukey $(P>0,05) . M I=$ dieta formulada com milho; $C S=$ substituição parcial do milho pela casca de soja; FGM = substituição parcial do milho pelo farelo de gérmen de milho. $\mathrm{CV}=$ coeficiente de variação.

Means within a row do not differ by Tukey test $(P>.05)$. MI = diet formulated with corn; CS = corn partial substitution for soybean hulls; FGM = corn partial substitution for corn germ meal. $C V=$ coefficient of variation. 
de sorgo e com milho (1,14 kg/dia), quando comparados a dietas com três níveis de substituição do milho pela casca de soja (33, 67 e 100\%), com média de $1,42 \mathrm{~kg} / \mathrm{dia}$. Restle et al. (2001), avaliando a substituição do grão de sorgo pela casca de soja, em dietas com $40 \%$ de concentrado, concluíram que a casca de soja promoveu melhor ganho de peso dos animais. No entanto, Gomes (1998) substituiu integralmente o milho pela casca de soja, em dieta para garrotes $1 / 2$ Nelore 1/2 Aberdeen Angus, confinados, sem qualquer efeito sobre o ganho de peso, com média de 1,35 $\mathrm{kg} / \mathrm{animal} / \mathrm{dia}$.

Os valores obtidos para a conversão alimentar entre as dietas experimentais não apresentaram diferença significativa. No entanto a dieta FGM apresentou valor $7 \%$ melhor de conversão alimentar, quando comparada à CS. Ferreira et al. (1999) avaliando diferentes níveis de concentrado nas rações de garrotes Simental x Nelore, utilizando como volumoso feno de capim coast-cross (Cynodon dactylon) e braquiária (Brachiaria decumbens), encontraram efeito linear decrescente para a conversão alimentar. O valor estimado de $44,3 \%$ de concentrado equivaleria à média observada neste experimento para a conversão alimentar $(9,17 \mathrm{~kg}$ MS ingerida/kg de ganho). No entanto a média de conversão alimentar encontrada neste experimento é numericamente maior àquelas apresentadas por Lema (2001) e Gomes (1998). Possivelmente, a composição genética dos animais, o consumo elevado e os baixos valores de digestibilidade das dietas possam ter influenciado a conversão alimentar.

Fisher \& Mühlbach (1999) avaliaram a substituição do grão de milho pela casca de soja nos níveis de $0,25,50$ e $75 \%$ em dietas de novilhas, sem raça definida, alimentadas com silagem de milho, e observaram que a substituição de até 75\% (30\% na dieta) não afetou o ganho de peso $(1,17 \mathrm{~kg} /$ dia $)$ e a conversão alimentar $(7,74 \mathrm{~kg}$ MS ingerida/kg de ganho). No entanto, Ludden et al. (1995) observaram decréscimo no ganho de peso de novilhos com o aumento do nível de casca de soja $(0,20,40$ e $60 \%)$ em dietas com $95 \%$ de concentrado e com milho como ingrediente principal, e relataram que a inclusão de pequena quantidade de casca de soja na dieta ( $<20 \%$ na MS) não afetou o desempenho dos animais, provavelmente pelo fato da casca de soja provocar menores transtornos metabólicos, aumentando a disponibilidade energética de outros ingredientes da ração.

R. Bras. Zootec., v.34, n.2, p.692-702, 2005
A eficiência alimentar de proteína bruta apresentou valor $12,9 \%$ e $7,4 \%$ mais elevado para a dieta FGM que os valores das dietas CS e MI, respectivamente, indicando que essa dieta apresentou uma melhor conversão de proteína em ganho de peso. Lema (2001) obteve valores de EAPB de 1,10; 0,98 e 0,79 em dietas com 12,14 e $16 \%$ de proteína bruta na ração, em bovinos confinados. Os melhores valores de eficiência protéica observados por Lema (2001) quando comparados aos encontrados neste trabalho, podem ser causados pela menor ingestão de MS (7,6 $\mathrm{kg} / \mathrm{dia}) \mathrm{e}$, conseqüentemente, menor ingestão de proteína bruta $(1,06 \mathrm{~kg} / \mathrm{dia})$.

As médias de peso final, peso corporal vazio, peso da carcaça quente, rendimento de carcaça (\% do peso final e \% do PCV), porcentagem de quebra no resfriamento, comprimento de carcaça, área de olho de lombo $\left(\mathrm{cm}^{2}\right.$ e $\mathrm{cm}^{2} / 100 \mathrm{~kg}$ de carcaça) e espessura de gordura subcutânea, de acordo com as dietas MI, CS e FGM, encontram-se na Tabela 6.

Observa-se que, apesar de não apresentar diferença significativa, o peso final dos animais alimentados com a dieta MI $(460,4 \mathrm{~kg})$ foi numericamente maior que o apresentado na dieta CS $(437,1$ $\mathrm{kg}$ ). No entanto os valores de PCV não apresentaram a mesma tendência, com valores médios muito próximos. Possivelmente, as características digestivas das diferentes dietas afetaram a quantidade de conteúdo gastrointestinal, até mesmo com o período de jejum alimentar de 14 horas utilizado nas pesagens.

Não houve diferença significativa para rendimento de carcaça, porém, quando expresso em relação ao peso final, a dieta CS apresentou rendimento de carcaça 1,96 unidades percentuais maior que a média das demais dietas. Possivelmente, características inerentes à dieta CS podem ter influenciado o rendimento expresso nessa forma, já que, quando expresso em relação ao $\mathrm{PCV}$, os valores de rendimento foram muito próximos (média de 63,11\% do PCV).

$\mathrm{O}$ valor médio obtido de rendimento de carcaça (52,8\%) é próximo ao observado por Franco (2001), que avaliaram diferentes teores de proteína bruta e balanço de proteína degradável e metabolizável em novilhos mestiços e apresentaram valor médio de $52,9 \%$. Jorge et al. (1999) citam que valores considerados bons para o rendimento de carcaça devem situar-se entre 53\% a 56\%. Segundo Prado et al. (2000), o rendimento de carcaça, além dos fatores de oscilação inerentes ao animal (genótipo, enchimento do rúmen, período de jejum e transporte), 
Tabela 6 - Médias de peso final, peso corporal vazio (PCV), peso da carcaça quente (PCQ), rendimento de carcaça (RC), porcentagem de quebra no resfriamento, comprimento de carcaça (CC), área de olho de lombo (AOL) e espessura de gordura subcutânea (EG), de acordo com as dietas experimentais

Table 6 - Means of final weight, empty body weight (PCV), hot carcass weight (PCQ), dressing percentage (RC), cooling loss percentage, carcass length (CC), Longissimus dorsi area (AOL) and fat thickness (EG), of each experimental diet

\begin{tabular}{|c|c|c|c|c|}
\hline & \multicolumn{3}{|c|}{$\begin{array}{l}\text { Dieta } \\
\text { Diet }\end{array}$} & \multirow[b]{2}{*}{$\mathrm{CV}(\%)$} \\
\hline & MI & $\mathrm{CS}$ & FGM & \\
\hline Peso final (kg) & 460,43 & 437,14 & 445,71 & 4,69 \\
\hline \multicolumn{5}{|l|}{ Final weight $(\mathrm{kg})$} \\
\hline Peso corporal vazio $(\mathrm{kg})$ & 376,02 & 371,87 & 372,90 & 4,83 \\
\hline \multicolumn{5}{|l|}{ Empty body weight $(\mathrm{kg})$} \\
\hline Peso de carcaça quente $(\mathrm{kg})$ & 239,79 & 236,79 & 232,93 & 5,90 \\
\hline \multicolumn{5}{|l|}{ Hot carcass weight $(\mathrm{kg})$} \\
\hline Rendimento de carcaça (\% PF) & 52,13 & 54,15 & 52,25 & 4,21 \\
\hline Dressing percentage (\% final weight) & & & & \\
\hline Rendimento de carcaça (\% PCV) & 63,77 & 63,13 & 62,43 & 2,83 \\
\hline \multicolumn{5}{|l|}{ Dressing percentage (\% empty body weight) } \\
\hline $\begin{array}{l}\% \text { de quebra no resfriamento } \\
\% \text { cooling loss }\end{array}$ & 2,51 & 2,67 & 2,55 & 13,13 \\
\hline Comprimento de carcaça $(\mathrm{cm})$ & 125,11 & 124,50 & 124,66 & 2,09 \\
\hline \multicolumn{5}{|l|}{ Carcass length $(\mathrm{cm})$} \\
\hline $\begin{array}{l}\text { Área de olho de lombo }\left(\mathrm{cm}^{2}\right) \\
\text { Longissimus dorsi area }\left(\mathrm{cm}^{2}\right)\end{array}$ & 65,82 & 66,12 & 58,85 & 11,79 \\
\hline $\begin{array}{l}\text { Área de olho de lombo }\left(\mathrm{cm}^{2} / 100 \mathrm{~kg} \text { de carcaça }\right) \\
\text { Longissimus dorsi area }\left(\mathrm{cm}^{2} / 100 \mathrm{~kg} \text { carcass }\right)\end{array}$ & 27,48 & 27,88 & 25,27 & 9,03 \\
\hline $\begin{array}{l}\text { Espessura de gordura }(\mathrm{mm}) \\
\text { Fat thickness }(\mathrm{mm})\end{array}$ & 4,19 & 5,01 & 4,90 & 23,80 \\
\hline
\end{tabular}

Médias em linhas não diferem entre si pelo teste de Tukey $(P>0,05)$. MI = dieta formulada com milho; CS = substituição parcial do milho pela casca de soja; FGM = substituição parcial do milho pelo farelo de gérmen de milho. CV = coeficiente de variação.

Means within a row do not differ by Tukey test $(P>.05)$. MI = diet formulated with corn; $C S=$ corn partial substitution for soybean hulls; FGM = corn partial substitution for corn germ meal. $\mathrm{CV}=$ coefficient of variation.

pode sofrer influência do local de abate, em função do maior ou menor grau de rigidez no processo de limpeza das carcaças.

Não houve diferença significativa $(\mathrm{P}>0,05)$ para a porcentagem de quebra no resfriamento entre as dietas. Esse fato já era esperado, porque o procedimento de resfriamento foi o mesmo para todas as carcaças. No entanto a média obtida $(2,58 \%)$ foi superior à média encontrada por Lema (2001), que obteve média de $0,87 \%$ de quebra, com 24 horas de resfriamento de 1 a $2^{\circ} \mathrm{C}$. Porém, Galvão et al. (1991), avaliando a porcentagem de quebra em bovinos machos Nelore e cruzados, apresentaram média de $2,10 \%$, valor mais próximo aos encontrados.

A média obtida de comprimento de carcaça $(124,8 \mathrm{~cm})$ é inferior à média relatada por Lema (2001) e Franco (2001), que encontraram, em bovinos cruzados, valores de $139,4 \mathrm{~cm}$ e $134,1 \mathrm{~cm}$, respectivamente. Esse menor valor de comprimento de carcaça indica o menor porte dos animais utilizados neste experimento.
Há indício de menor conversão em tecido muscular na dieta FGM em comparação às demais, graças ao valor numericamente menor de $\operatorname{AOL}\left(58,9 \mathrm{~cm}^{2}\right)$, que está altamente correlacionado com o peso dos cortes cárneos (Luchiari Filho, 2000), considerando a espessura de gordura praticamente constante. Thiago et al. (2000), substituindo o milho pelo sorgo ou pela casca de soja, em dietas para animais Nelore com peso inicial de $386 \mathrm{~kg}$, alimentados com silagem de sorgo, não observaram efeito sobre as características de carcaça e encontraram valores médios superiores aos encontrados neste estudo $\left(55,6 \%, 73 \mathrm{~cm}^{2}\right.$ e 6,6 $\mathrm{mm}$ vs $52,8 \%, 63,6 \mathrm{~cm}^{2}$ e $4,7 \mathrm{~mm}$ para rendimento de carcaça, AOL e espessura de gordura, respectivamente).

A média de AOL encontrada neste experimento (26,9 $\mathrm{cm}^{2} / 100 \mathrm{~kg}$ de carcaça) pode ser considerada satisfatória. No entanto, é inferior à relatada por Lema (2001), de 29,3 $\mathrm{cm}^{2} / 100 \mathrm{~kg}$ de carcaça, em bovinos cruzados. Luchiari Filho (2000) apresentou resultados de avaliação de 826 carcaças de animais 
cruzados, com valores médios de 70,2 e $27,9 \mathrm{~cm}^{2} / 100 \mathrm{~kg}$ de carcaça de AOL.

A média de 4,7 $\mathrm{mm}$ de espessura de gordura subcutânea está acima do valor mínimo necessário (3 mm) citado por Luchiari Filho (2000). Segundo esse autor, gordura subcutânea em pequena quantidade ocasiona problemas no manuseio da carcaça e encurtamento celular durante a estocagem, em decorrência do frio e do paladar da carne.

As dietas com milho e farelo de gérmen de milho propiciaram ganhos e conversões alimentares muito semelhantes, no entanto, a AOL obtida com a dieta FGM foi $10,6 \%$ inferior e a espessura de gordura $17,0 \%$ superior em relação à $\mathrm{MI}$, sugerindo maior deposição de gordura com a dieta com farelo de gérmen de milho.

\section{Conclusões}

O grão de milho pode ser substituído parcialmente (50\%) pela casca de soja e pelo farelo de gérmen de milho em dietas para novilhos em confinamento sem afetar o desempenho e as características de carcaça, permitindo que a escolha entre esses ingredientes seja realizada por meio de análise econômica.

\section{Agradecimento}

À Caramuru Alimentos Ltda. pela doação dos ingredientes: farelo de girassol, casca de soja e farelo de gérmen de milho.

\section{Literatura Citada}

AGRIANUAL 2002. Anuário da Agricultura Brasileira, São Paulo:FNP - Consultoria e Comércio, 2002. 536p.

ASSOCIATION OF OFFICIAL ANALYTICAL CHEMISTS AOAC. Official methods of analysis. 16.ed. Washington, D.C.: 1995.1025 p.

BERNARD, J.K.; McNEIL, W.W. Effect of high fiber energy supplements on nutrient digestibility and milk production of lactating dairy cows. Journal of Dairy Science, v.74, n.3, p.991-995, 1991.

BRODERICK, G.A.; CLAYTON, M.K. A statistical of animal and nutritional factors influencing concentrations of milk urea nitrogen. Journal of Dairy Science, v.80, n.11, p.2964-2971, 1997.

FAULKNER, D.B.; HUMMEL, D.F.; BUSKIRK, D.D. et al. Performance and nutrient metabolism by nursing calves supplemented with limited or unlimited corn or soyhulls. Journal of Animal Science, v.72, n.2, p.470-477, 1994.

FEIJÓ, G.L.D.; SILVA, J.M.; THIAGO, L.R.L.S. Efeito bioeconômico de níveis de concentrado no confinamento de novilhos. Campo Grande: Embrapa Gado de Corte, 1998.30p.
FERREIRA, M.A.; VALADARES FILHO, S.C.; COELHO DA SILVA, J.F. et al. Consumo, conversão alimentar, ganho de peso e características da carcaça de bovinos $\mathrm{F}_{1}$ Simental $\mathrm{x}$ Nelore. Revista Brasileira de Zootecnia, v.28, n.2, p.343351, 1999.

FISHER, V.; MÜHLBACH, P.R.F. Substituição do grão de milho por casca de soja no desempenho de novilhas de corte confinadas. Pesquisa Agropecuária Gaúcha, v.5, n.1, p.143148, 1999.

FRANCO, G.L. Avaliação da proteína degradável no rúmen e da proteína metabolizável segundo o sistema de Cornell em rações de novilhos confinados. 2001. 74 p. Tese (Doutorado em Produção Animal) - Faculdade de Ciências Agrárias e Veterinárias. Universidade Estadual Paulista, Jaboticabal - SP, 2001.

GALATI, R.L.; EZEQUIEL, J.M.B; MENDES, A.R. et al. Cinética da digestão ruminal in situ de fontes energéticas fornecidas a bovinos. In: REUNIÃO ANUAL DA SOCIEDADE BRASILEIRA DE ZOOTECNIA, 39, 2002, Recife. Anais... Recife: Technomedia, 2002 a. CD-ROM. Nutrição de Ruminantes.

GALATI, R.L.; EZEQUIEL, J.M.B; MENDES, A.R. et al. Cinética da digestão ruminal in situ do farelo de girassol utilizado em dietas para bovinos. In: REUNIÃO ANUAL DA SOCIEDADE BRASILEIRA DE ZOOTECNIA, 39., 2002, Recife. Anais... Recife:Technomedia, 2002b. CD-ROM. Nutrição de Ruminantes.

GALATI, R.L.; EZEQUIEL, J.M.B; MENDES, A.R. et al. Influência de diferentes fontes energéticas sobre os valores de $\mathrm{pH}$ e concentrações ruminais de nitrogênio amoniacal no rúmen e no intestino. In: REUNIÃO ANUAL DA SOCIEDADE BRASILEIRA DE ZOOTECNIA, 39, 2002, Recife. Anais... Recife: Technomedia, 2002c. CD-ROM. Nutrição de Ruminantes.

GALVÃO, J.G.; FONTES, C.A.A.; PIRES, C.C. et al. Ganho de peso, consumo e conversão alimentar em bovinos não castrados, de três grupos raciais, abatidos em diferentes estágios de maturidade (estudo 1). Revista da Sociedade Brasileira de Zootecnia, v.20, n.5, p.494-501, 1991.

GOMES, I.P.O. Substituição do milho pela casca de soja em dietas com diferentes proporções de volumoso: concentrado para bovinos em confinamento. Jaboticabal: Universidade Estadual Paulista, 1998. 84p. Tese (Doutorado em Produção Animal) - Universidade Estadual Paulista, 1998.

GRIGSBY, K.N.; KERLEY, M.S.; PATERSON, J.A. et al. Combinations of starch and digestible fiber in supplements for steers consuming a low-quality bromegrass hay diet. Journal of Animal Science, v.71, n.4, p.1057-1064, 1993.

GUIA. 2000. Guia Médico Veterinário 2000. São Paulo: Mary. 444p.

HOOVER, W.H. Chemical factores involved in ruminal fiber digestion. Journal of Dairy Science, v.69, n.6, p.27552766, 1986.

JORGE, A.M.; FONTES, C.A.A.; PAULINO, M.F. et al. Desempenho produtivo de animais de quatro raças zebuínas, abatidas em três estádios de maturidade. 1. Ganho de peso e de carcaça e eficiência de ganho. Revista Brasileira de Zootecnia, v.27, n.4, p.766-769, 1998.

JORGE, A.M.; FONTES, C.A.A.; PAULINO, M.F. et al. Desempenho produtivo de animais de quatro raças zebuínas, abatidas em três estádios de maturidade. 2. Características de carcaça. Revista Brasileira de Zootecnia, v.28, n.2, p.381-387, 1999. 
KENNEDY, P.M.; MILLIGAN, L.P. The degradation and utilization of endogenous urea in the gastrointestinal tract of ruminants: a review. Canadian Journal of Animal Science, v.60, n.2, p.205-221, 1980.

LEMA, A.C.F. Produção e qualidade de carcaças de bovinos terminados em confinamento. Jaboticabal: Universidade Estadual Paulista, 2001. 95p. Tese (Doutorado em Produção Animal) - Universidade Estadual Paulista, 2001.

LÓPEZ, J.; STUMPF Jr., W. Influência do grão de sorgo como fonte de amido em ovinos alimentados com feno. Parâmetros plasmáticos. Revista Brasileira de Zootecnia, v.29, n.4, p.1183-1190, 2000.

LYCOS, T.; VARGA, G.A.; CASPER, D. Varying degradation rates of total nonstructural carbohydrates: effects on ruminal fermentation, blood metabolites, and milk production and composition in high producing Holstein cows. Journal of Dairy Science, v.80, n.12, p.3341-3355, 1997.

LUCHIARI FILHO, A. Pecuária da carne bovina. São Paulo: A Luchiari Filho, 2000. 134p.

LUDDEN, P.A.; CECAVA, M.J.; HENDRIX, K.S. The value of soybean hulls as a replacement for corn in beef cattle diets formulated with or without added fat. Journal of Animal Science, v.73, n.9, p.2706-2711, 1995.

MANSFIELD, H.R.; STERN, M.D. Effects off soybean hulls and lignosulfonate-treated soybean meal on ruminal fermentation in lactating dairy cows. Journal of Dairy Science, v.77, n.4, p.1070-1083, 1994.

MENDES, A.R.; EZEQUIEL, J.M.B.; GALATI, R.L. et al. Consumo e digestibilidade aparente total e parcial de dietas utilizando farelo de girassol e três fontes de energia em novilhos confinados. Revista Brasileira de Zootecnia, v.34, n.2, p.611-623, 2005.

MERTENS, D. R. Rate and extent of digestion. In: FORBES, J. M.; FRANCE, J. (Eds.) Quantitative aspects of ruminant digestion and metabolism. Wallingford: $\mathrm{CAB}$ International, 1993. p.13-51.

MILTON, C.T.; BRANDT, R.T.; TITGEMEYER, E.C. et al. Effect of degradable and escape protein and roughage type on performance and carcass characteristics of finishing yearling steers. Journal of Animal Science, v.75, n.3, p.2834-2840, 1997.

MIRANDA, L. F. et al. Efeito da proteína dietética na concentração da uréia plasmática de novilhas. In: REUNIÃO DA SOCIEDADE BRASILEIRA DE ZOOTECNIA, 35., 1998, Botucatu. Anais... Botucatu: Sociedade Brasileira de Zootecnia, 1998. p.71-73 (CD-ROM).

NATIONAL RESEARCH COUNCIL - NRC. Nutrient requirements of beef cattle. 7.ed. Washington, D.C.: National Academic Press, 1996. 242p.

PAYNE, J.M.; PAYNE, S. The metabolic profile test. Oxford: Oxford University Press. 1987. 179p.

PRADO, I.N.; PINHEIRO, A.D.; ALCALDE, C.R. et al. Níveis de substituição do milho pela polpa de citrus peletizada sobre o desempenho e características de carcaça de bovinos mestiços confinados. Revista Brasileira de Zootecnia, v.29, n.6, p.2135-2141, 2000.
RESTlE, J.; ALVES FILHO, D. C.; BRONDANI, I. L. et al. Efeito da substituição do grão de sorgo pela casca de soja no desempenho de novilhos em confinamento. In: REUNIÃO ANUAL DA SOCIEDADE BRASILEIRA DE ZOOTECNIA, 38., 2001, Piracicaba. Anais... São Paulo: Sonopress, 2001. p.1330-1331 CD-ROM. Áreas Técnicas. Nutrição de Ruminantes.

RICHARDSON, C.R.; BURLLE, R.N.; RATELIFF, R.K. et al. Sunflower as a protein supplement for growing ruminants. Journal of Animal Science, v.53, n.3, p.557-563, 1981.

STATISTICAL ANALYSIS SISTEMS - SAS Language Guide v.6, 3.ed. Cary: 1995. 530p.

SILVA, D.J. Análise de alimentos (Métodos químicos e biológicos). 2 ed. Viçosa, MG: Universidade Federal de Viçosa, 1990. 165p.

SIMAS, J.M.C.; PIRES, A.V.; RIBEIRO, C.V.M. et al. Efeito de fontes de amido sobre parâmetros sanguíneos e ruminais de vacas holandesas. In: REUNIÃO ANUAL DA SOCIEDADE BRASILEIRA DE ZOOTECNIA, 37., 2000, Viçosa, MG. Anais... São Paulo: Gnosis, 2000. CD-ROM. Áreas Técnicas. Nutrição de Ruminantes.

SMITH, B.P. Tratado de medicina interna de grandes animais. São Paulo:Manole, 1993. 1660p.

STEEN, R.W.J. A comparison of soya-bean, sunflower and fish meals as protein supplements for yearling cattle offered grass silage-based diets. Animal Production, v.48, n.1, p.81-89, 1989.

SVENDSEN, P. Introducción a la fisiología animal. Zaragoza: Acribia, 1976. 216p.

THIAGO, L.R.L.S.; SILVA, J.M.; FEIJÓ, G.L.D. et al. Substituição do milho pelo sorgo ou casca de soja em dietas para engorda de bovinos em confinamento. In: REUNIÃO ANUAL DA SOCIEDADE BRASILEIRA DE ZOOTECNIA, 37., 2000. Viçosa. Anais... São Paulo:Gnosis, 2000. CD-ROM. Áreas Técnicas. Nutrição de Ruminantes.

VINCENT, I.C.; HILL, R.; CAMPLING, R.C. A note on the use of rapeseed, sunflower and soya-bean meals as protein sources in compound foods for milking cattle. Animal Production, v.50, n.3, p.541-543, 1990.

WALDO, D.R. Extent and partition of cereal grain starch digestion in ruminants. Journal of Animal Science, v.37, n.4, p.1062-1074, 1973.

WEEKS, T.C.E. Hormonal control of glucose metabolism. In: TSUDA, T.; SASAKI, Y.; KAWASHIMA, R. (Eds.) Physiological aspects of digestion and metabolism in ruminants. San Diego: Academic Press. 1991. p.183-200.

Recebido em: 20/10/03 Aceito em: 16/08/04 